Www.jmscr.igmpublication.org

Impact Factor (SJIF): 6.379

Index Copernicus Value: 79.54

ISSN (e)-2347-176x ISSN (p) 2455-0450

crossrefDOI: https://dx.doi.org/10.18535/jmscr/v6i11.05

Journal Of Medical Science And Clinical Research

IGM Publication

An Official Publication of IGM Publication

\title{
Glycosylated Hemoglobin and Left Ventricular Diastolic Dysfunction in Type 2 Diabetes Mellitus Patients
}

\author{
Authors \\ Dr Raghib Hasan ${ }^{1}$, Dr M. Ghosh², Dr P. K. Agrawal ${ }^{3}$, Dr Taskeen Ahmad ${ }^{4}$, \\ Dr Ashique Saikh ${ }^{5}$, Dr Farogh Haidry ${ }^{6}$, Dr Tabrez Alam ${ }^{7}$ \\ ${ }^{1,5,6,7}$ Post Graduate Trainee, ${ }^{2}$ Professor, ${ }^{3}$ Professor \& Head, ${ }^{4}$ Associate Professor, \\ Department of Medicine, Katihar Medical College, Katihar, India
}

\begin{abstract}
Introduction: Diabetes Mellitus (DM) refers to a group of common metabolic disorders that share the phenotype of hyperglycemia. The diastolic abnormalities are present in diabetic patients without overt diabetic complications of cardiovascular system, it is the earliest and specific functional abnormality in diabetic cardiomyopathy and can affect patients who are free of macrovascular complications, even in newly diagnosed diabetes mellitus patients or in those with a disease duration of less than 1 year. Diastolic dysfunction (DD) has been broadly defined as left ventricular diastolic dysfunction (LVDD) indicating a functional abnormality of diastolic relaxation, elasticity or distensibility of the left ventricle (LV), regardless of whether the left ventricle ejection fraction (LVEF) is normal or abnormal and whether the patient is symptomatic or not.

Aims and Objectives: (a) To assess the prevalence of diastolic dysfunction in patients with type 2 diabetes. (b) To assess the correlation of diastolic dysfunction and HbAlc levels.

Method: 100 patients of Type-2 DM attending the medicine outpatient/inpatient department of Katihar Medical College and Hospital were shortlisted for Doppler echocardiography and HbAlclevels.

Inclusion criteria: Age group 30-55yrs independent of sex, clinically proven case of type-2 diabetes mellitus. Exclusion criteria: patients with systemic hypertension, thyroid disease, stroke, peripheral vascular disease, family history of heart disease, pregnancy and patients not willing to give consent for the study.

Results: In the present study among 100 diabetic patients 57 were positive and 43 were negative for diastolic dysfunction. E/A was 1.02 and 1.23 in diastolic dysfunction positive and negative patients respectively. There was significant reduction in E/A ratio in patients with diastolic dysfunction, $(p<0.001) .6$ patients belong to group with HbAlc\% <5.6 out of which 4 were positive and 2 were negative for diastolic dysfunction, 28 patients belong to HbAlc\% range of $5.7-6.4$ out of which 4 were positive and 24 were negative and 66 patients belong to HbAlc\% range of $>6.4$ out of which 49 were positive and 17 were negative for diastolic dysfunction. Ejection fraction percentages were 63.40 in diastolic dysfunction positive and 68.90 in negative patients.

Conclusion: HbAlc\% measurement can be a very good indicator of long-term prognosis in diabetics. Even young diabetics with normal systolic ventricular function have diastolic dysfunction, which serves as a indicator of a diabetic cardiomyopathy. The results from this study reinforce the important role of Doppler echocardiography to evaluate the heart diastolic function parameters in diabetics. Early diagnosis and therapeutic interventions in diabetes mellitus with regular follow-up before the deleterious cardiac sequelae become established clinically, modulate the cardiac metabolism and prevent heart failure.
\end{abstract}




\section{Introduction}

Diabetes Mellitus (DM) refers to a group of common metabolic disorders that share the phenotype of hyperglycemia. ${ }^{1}$ Diabetes has become a leading cause of premature death, disability and high health care costs. It is a silent killer disease.

Worldwide, there are approximately 194 million adult cases of type 2 diabetes and this number is expected to increase to 333 million by 2025 . There are approximately 33 million diabetics in India presently and this number is expected to reach 79.4 million in $2030 .^{2}$ India will have the largest number of diabetic subjects in the world by 2025 and one out of 5 diabetic patients in the world will be an Indian. India is going to be the "Diabetic capital of the world". One of the important factors contributing to increased prevalence of type 2 diabetes in Asian Indians is the fact that they have a greater degree of insulin resistance compared to Caucasians. ${ }^{3-4}$ Aging, obesity, diabetes mellitus, cardiac ischemia, increase in blood pressure, aortic stenosis, myocardial diseases, endomyocardial disorders, pericardial effusion and constrictive pericarditis are various common causes of left ventricular Diastolic Dysfunction. ${ }^{5-6}$ Despite similar left ventricular systolic dysfunction, patients with diabetes have more pronounced heart failure symptoms, use more diuretics, and have an adverse prognosis compared with those without diabetes; one putative explanation for these discrepancies is diastolic dysfunction of the left ventricle in diabetes mellitus. ${ }^{7}$ Left ventricular diastolic dysfunction thus represent the first stage of diabetic cardiomyopathy preceding changes in systolic function, reinforcing the importance of early examination of ventricular function in individuals with diabetes. ${ }^{8-9}$

The diastolic abnormalities are present in diabetic patients without overt diabetic complications of cardiovascular system, it is the earliest and specific functional abnormality in diabetic cardiomyopathy and can affect patients who are free of macrovascular complications, even in newly diagnosed diabetes mellitus patients or in those with a disease duration of less than 1 year. ${ }^{10 a-b}$ Diastolic dysfunction refers to a condition in which abnormalities in mechanical function are present during diastole. The causes of diastolic dysfunction may be subdivided into a decrease in passive myocardial diastolic compliance, and impairment in active LV relaxation. Abnormalities in diastolic function may occur in the presence or absence of a clinical syndrome of heart failure and with normal or abnormal systolic function. Therefore, whereas diastolic dysfunction describes an abnormal mechanical property, diastolic heart failure describes a clinical syndrome. ${ }^{8}$

DCCT trail is one of the largest prospective study in the field of diabetes showed diabetics are 5 times more prone for acute myocardial infarction and death. HOPE study findings also suggest the same.

Subclinical abnormalities of left ventricular function are recognized in both type 1 and type 2 diabetics. Shapiro et al found that asymptomatic diabetic subjects had impaired left ventricular relaxation on digitalized $\mathrm{M}$ - mode echocardiography as compared with non-diabetic controls. Studies using Doppler echocardiography have confirmed the findings of abnormal diastolic function as an early indicator of cardiomyopathy in asymptomatic patients. ${ }^{11}$

This study titled "Glycosylated Hemoglobin and Left Ventricular Diastolic Dysfunction in Type 2 Diabetes Mellitus Patients" was undertaken to evaluate LV diastolic function in diabetics and to assess the correlation of diastolic dysfunction and HbA1c levels.

\section{Method}

100 patients of Type-2 DM attending the medicine outpatient/inpatient department of Katihar Medical College and Hospital were shortlisted for Doppler echocardiography and HbA1clevels.

\section{Inclusion criteria}

(a) age group 30-55yrs independent of sex, 
(b) clinically proven case of type-2 diabetes mellitus.

Exclusion criteria: (a). patients with systemic hypertension, thyroid disease, stroke, peripheral vascular disease,

(b). family history of heart disease

(c). pregnancy,

(d). patients not willing to give consent for the study.

It is an observational study. Subjects were enrolled in the study based on the inclusion and exclusion criteria. The selected subjects were briefed about the nature of the study and a written informed consent was obtained before the subject was enrolled in this study. Demographic data like gender, age etc. was collected along with the relevant history and recorded in predesigned proforma. A thorough clinical examination was conducted and findings were also recorded.

Patients with type-2 diabetes evaluated for Doppler echocardiography and HbA1c levels. In Doppler study following values will be studied.

- E- Peak velocity of early mitral flow (ECms-1)

- Peak velocity of late mitral flow (A-Cms1)

- E/A ratio

- PHT- Pressure half - time (PHT - ms)

- IRT- Isovolumic relaxation time (IRT $\mathrm{ms}$ )

- $\mathrm{EF} \%$ - Ejection fraction

\section{Investigations}

- FBS, PPBS, HbA1c\%

- Urine routine, ECG

- Blood urea, serum creatinine, serum cholesterol,

- Chest X-ray PA view, ultrasonography whole abdomen, other investigations as and when needed.

Total hemoglobin and $\mathrm{HbA} 1 \mathrm{c}$ concentrations are determined after haemolysis of the anticoagulated whole blood specimen. Total hemoglobin is measured colorimetrically. HbA1c is determined immunoturbidimetrically. The ratio of both concentrations yields the final percent $\mathrm{HbA} 1 \mathrm{c}$ results. Blood glucose by glucose oxidase/ peroxidase enzymatic method.The data collected were analysed and expressed as Mean \pm SD. Chi square test and Student's unpaired test were applied. The results were tabulated, graphically represented and analysed.

\section{Results}

In the present study among 100 patients 34 belong to age group of $30-39$, out of which 20 were positive and 14 were negative for diastolic dysfunction. 32 patients belong to $40-49$ age group, out of which 21 were positive and 11 were negative for diastolic dysfunction.34 patients belong to 50 - 55 age group, out of which 16 were positive and 18 were negative for diastolic dysfunction.

Mean age is 43.00 years and standard deviation of 6.5 in diastolic dysfunction positive group.

Mean age is 45.5 years and standard deviation of 7.4 in diastolic dysfunction negative group.

Mean difference is $2.5, \mathrm{t}$ value is 2.21 and $\mathrm{P}$ value 0.04(S).

In the present study 60 patients were males out of which 37 were positive and 23 were negative for diastolic dysfunction. 40 patients were females out of which 20 were positive and 20 were negative for diastolic dysfunction. Chi-square test is 1.48 and $\mathrm{P}$ value is $0.22(\mathrm{NS})$.

In the present study 6 patients belong to group with $\mathrm{HbA} 1 \mathrm{c} \%<5.6$ out of which 4 were positive and 2 were negative for diastolic dysfunction. 28 patients belong to $\mathrm{HbA} 1 \mathrm{c} \%$ range of $5.7-6.4$ out of which 4 were positive and 24 were negative for diastolic dysfunction. 66 patients belong to $\mathrm{HbA1c} \%$ range of $>6.4$ out of which 49 were positive and 17 were negative for diastolic dysfunction.

Chi-square test in 42.63 and $\mathrm{P}$ value is $<0.001$ (HS).

E/A was 1.02 and 1.23 in diastolic dysfunction positive and negative patients respectively. There was significant reduction in E/A ratio in patients with diastolic dysfunction. $(\mathrm{p}<0.001)$ 
Pressure half time were 58.80 in diastolic dysfunction positive and 54.18 in negative patients. There was significant increase in PTH in patients with diastolic dysfunction $(\mathrm{p}=0.01)$

Isovolumic relaxation time were 83.53 in diastolic dysfunction positive and 75.63 in negative

Table- 1

Age Distribution

\begin{tabular}{|l|c|c|c|c|}
\hline \multirow{2}{*}{$\begin{array}{c}\text { Age Group } \\
\text { (Yrs.) }\end{array}$} & & \multicolumn{2}{|c|}{ DD Group } & \multirow{2}{*}{ Total } \\
\cline { 2 - 4 } $30-39$ & No & 20 & 14 & 34 \\
\cline { 2 - 4 } & $\%$ & $35.0 \%$ & $32.5 \%$ & $34.0 \%$ \\
\hline \multirow{2}{*}{$40-49$} & No & 21 & 11 & 32 \\
\cline { 2 - 4 } & $\%$ & $36.8 \%$ & $25.5 \%$ & $32.0 \%$ \\
\hline \multirow{2}{*}{$50-55$} & No & 16 & 18 & 34 \\
\cline { 2 - 4 } & $\%$ & $28.0 \%$ & $41.8 \%$ & $34.0 \%$ \\
\hline \multirow{2}{*}{ Total } & No & $\mathbf{5 7}$ & $\mathbf{4 3}$ & $\mathbf{1 0 0}$ \\
\cline { 2 - 4 } & $\mathbf{\%}$ & $\mathbf{1 0 0 \%}$ & $\mathbf{1 0 0 \%}$ & $\mathbf{1 0 0 \%}$ \\
\hline
\end{tabular}

Table-2

Sex Distribution

\begin{tabular}{|l|c|c|c|c|}
\hline \multirow{2}{*}{ Sex } & & \multicolumn{2}{|c|}{ DD Group } & \multirow{2}{*}{ Total } \\
\cline { 3 - 4 } & & DD + & DD - & \\
\hline \multirow{2}{*}{ Male } & No. & 37 & 23 & 60 \\
\cline { 2 - 5 } & $\%$ & $64.9 \%$ & $53.4 \%$ & $60.0 \%$ \\
\hline \multirow{2}{*}{ Female } & No. & 20 & 20 & 40 \\
\cline { 2 - 5 } & $\%$ & $35.0 \%$ & $46.5 \%$ & $40.0 \%$ \\
\hline \multirow{2}{*}{ Total } & No. & 57 & 43 & 100 \\
\cline { 2 - 5 } & $\%$ & 100.0 & 100.0 & 100.0 \\
\hline
\end{tabular}

Table - 3

Comparison of $\mathrm{HbA} 1 \mathrm{c} \%$ Levels

\begin{tabular}{|l|c|c|c|c|}
\hline \multirow{2}{*}{$\begin{array}{c}\text { HbA1c } \\
\text { N }\end{array}$} & \multicolumn{2}{|c|}{ DD Group } & \multirow{2}{*}{ Total } \\
\cline { 2 - 5 } & & DD + & DD - & \\
\hline \multirow{2}{*}{5.6} & No. & 4 & 2 & 6 \\
\cline { 2 - 5 } & $\%$ & $7.0 \%$ & $4.0 \%$ & $6.0 \%$ \\
\hline \multirow{2}{*}{$5.7-6.4$} & No. & 4 & 24 & 28 \\
\cline { 2 - 5 } & $\%$ & $7.0 \%$ & $55.8 \%$ & $28.0 \%$ \\
\hline \multirow{2}{*}{6.4} & No. & 49 & 17 & 66 \\
\cline { 2 - 5 } & $\%$ & $85.9 \%$ & $39.5 \%$ & $66.0 \%$ \\
\hline \multirow{2}{*}{ Total } & No. & $\mathbf{5 7}$ & $\mathbf{4 3}$ & $\mathbf{1 0 0}$ \\
\cline { 2 - 5 } & $\mathbf{\%}$ & $\mathbf{1 0 0 \%}$ & $\mathbf{1 0 0 \%}$ & $\mathbf{1 0 0 \%}$ \\
\hline
\end{tabular}

patients. There was significant increase in IRT in patients with diastolic dysfunction $(\mathrm{p}=0.001)$.

Ejection fraction percentages were 63.40 in diastolic dysfunction positive and 68.90 in negative patients. There was significant reduction in $\mathrm{EF} \%$ in patients with diastolic dysfunction $(\mathrm{p}=0.001)$.

\section{Graph - 1}

Age Distribution

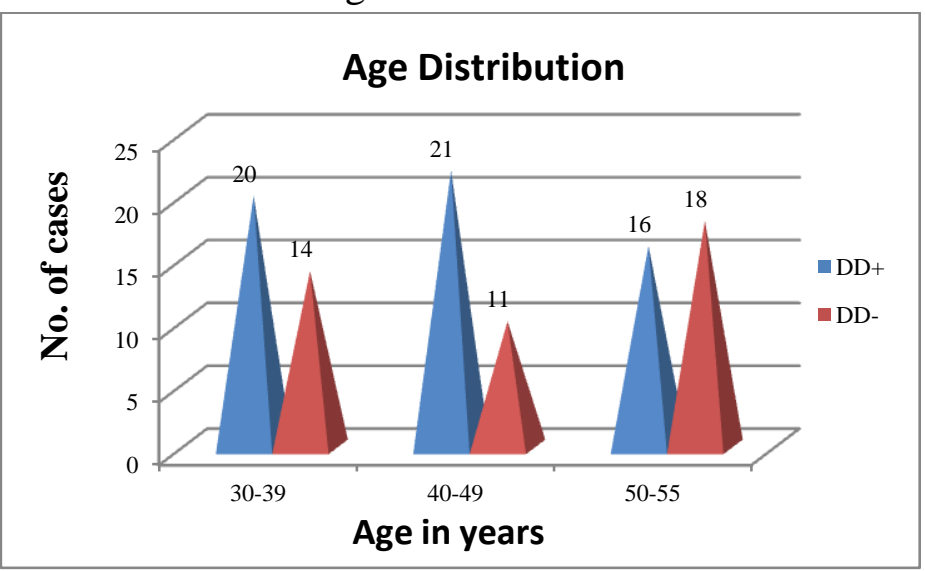

Graph-2

Sex Distribution

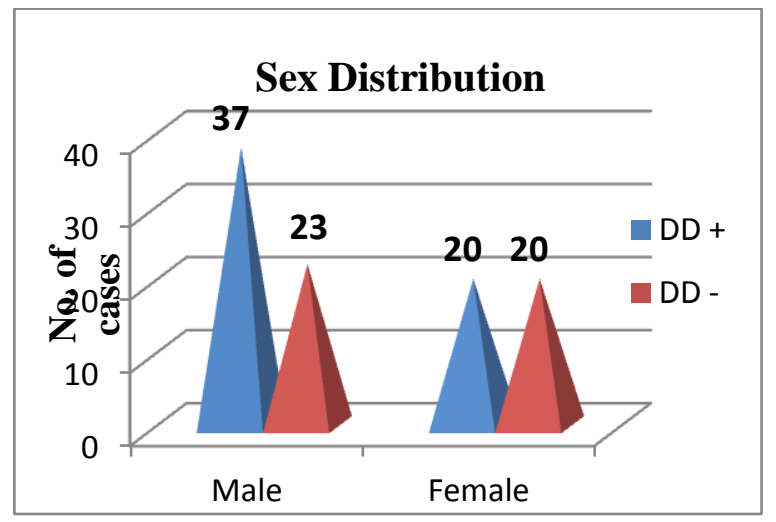

Graph-3

Comparison of $\mathrm{HbA} 1 \mathrm{c} \%$ Levels

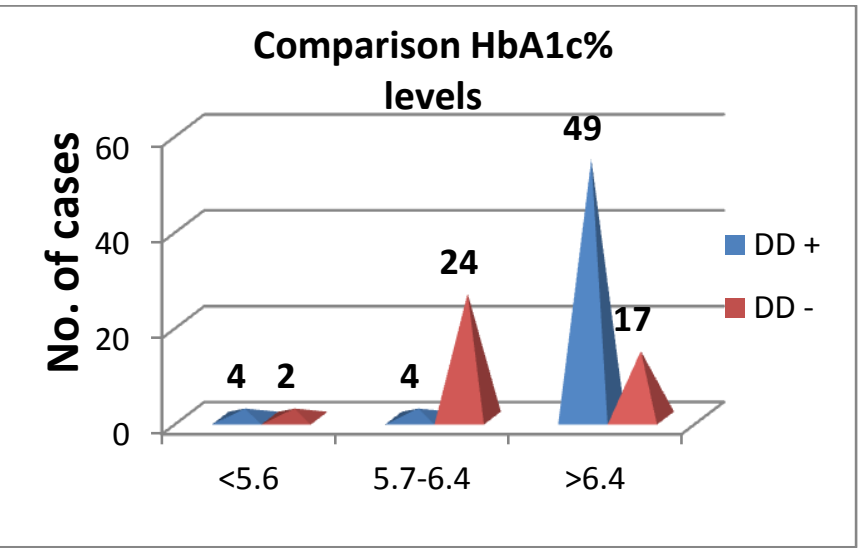


Table 4 Comparison of Left Ventricular Filling Patterns

\begin{tabular}{|l|c|c|c|c|c|c|cc|}
\hline \multirow{2}{*}{ Variable } & \multicolumn{2}{|c|}{ DD +} & \multicolumn{2}{|c|}{ DD - } & \multicolumn{3}{c|}{ DD+ v/s DD- } \\
\cline { 2 - 12 } & & & & & Mean diff & & & \\
& Mean & SD & Mean & SD & & t value * & P value \\
\hline E & 69.44 & 9.08 & 73.77 & 6.68 & -4.33 & -2.61 & 0.01 & $\mathrm{~S}$ \\
\hline A & 67.63 & 7.82 & 59.91 & 9.46 & 7.72 & 4.46 & 0.00 & $\mathrm{HS}$ \\
\hline E/A Ratio & 1.02 & 0.20 & 1.23 & 0.24 & -0.21 & -3.64 & 0.00 & $\mathrm{~S}$ \\
\hline PHT & 58.80 & 8.83 & 54.18 & 7.20 & 4.62 & 2.77 & 0.01 & $\mathrm{~S}$ \\
\hline IRT & 83.53 & 6.98 & 75.63 & 13.71 & 7.90 & 3.77 & 0.00 & $\mathrm{HS}$ \\
\hline LVIDd & 4.56 & 0.59 & 4.29 & 0.60 & 0.26 & 2.18 & 0.03 & $\mathrm{~S}$ \\
\hline LVIDs & 3.17 & 0.52 & 2.91 & 0.48 & 0.27 & 2.62 & 0.01 & $\mathrm{~S}$ \\
\hline RVIDd & 9.93 & 1.12 & 10.48 & 1.06 & -0.55 & -2.45 & 0.02 & $\mathrm{~S}$ \\
\hline LAcm & 4.81 & 6.58 & 3.14 & 0.30 & 1.67 & 1.64 & 0.10 & $\mathrm{NS}$ \\
\hline AOcm & 2.74 & 0.27 & 3.93 & 5.90 & -1.20 & -1.54 & 0.13 & $\mathrm{NS}$ \\
\hline EF \% & 63.40 & 7.97 & 68.90 & 9.77 & -5.50 & -3.06 & 0.00 & $\mathrm{~S}$ \\
\hline
\end{tabular}

* Unpaired t test, S: Significant, NS: Non-significant, HS: Highly significant

\section{Discussion}

In diabetes mellitus, DD results from abnormal myocardial active relaxation and an increase in passive stiffness due to metabolic derangements, microvascular disease, autonomic dysfunction and structural remodelling. ${ }^{14,15}$ Prevalence of LVDD in $\mathrm{T} 2 \mathrm{DM}$ varies from $47 \%$ to $71 \%$ in different studies.

In our present study the patients with above conditions which affect LV diastolic function were avoided. Patients with systolic dysfunction also were avoided. It was found out that 57 patients in our study group comprising of 100 patients had significant LV diastolic dysfunction in which 37 were male and 20 were female.

The mean peak velocity of early mitral flow (E) value was 69.44. The mean peak velocity of late mitral flow (A) value 67.63, pressure half time (PHT) was 58.80, Isovolumic relaxation time (IRT) was 83.53 , E/A ratio was 1.02 , and left ventricular ejection fraction (EF\%) was $63.40 \%$. There was significant correlation between diastolic dysfunction and HbA1c $(\mathrm{P}=0.001)$.

Sharavanan TKV et al reported prevalence of diastolic dysfunction in diabetic patients was 66 $(55.0 \%) .{ }^{12}$ In a study performed on Diastolic Dysfunction in Newly Diagnosed Type 2 Diabetes
Mellitus and its Correlation with Glycosylated Haemoglobin (HbA1C) by Chaudhary AK et al, the observations of $\mathrm{HbA1C}$ were directly proportional to the incidence of diastolic dysfunction. $^{13}$

In another study Patil et al found out the incidence of LV diastolic dysfunction in diabetic patient and its relation to age, duration of diabetes mellitus. $54 \%$ case and $11 \%$ healthy subjects had diastolic dysfunction. Patients with diabetic duration of 11 to 15 years showed high prevalence of diastolic dysfunction $(\mathrm{P}<0.05){ }^{16}$

"Each $1 \%$ increase in $\mathrm{HbA1c}$ level has been associated with an $8 \%$ increase in the risk of heart failure and $\mathrm{HbA} 1 \mathrm{c}>8$ has also been associated with diastolic dysfunction, although the glycemic control may not reverse the diastolic dysfunction. $^{17}$

\section{Conclusion}

$\mathrm{HbA1c} \%$ measurement can be a very good indicator of long-term prognosis in diabetics. Even young diabetics with normal systolic ventricular function have diastolic dysfunction, which serves as an indicator of a diabetic cardiomyopathy. The results from this study reinforce the important role of Doppler 
echocardiography to evaluate the heart diastolic function parameters in diabetics. Early diagnosis and therapeutic interventions in diabetes mellitus with regular follow-up before the deleterious cardiac sequelae become established clinically, modulate the cardiac metabolism and prevent heart failure.

\section{Bibliography}

1. Harrison Principles of Internal Medicine, 19th edition, pub. Mc Graw Hill, chapter 417,p.2399,2401

2. World Health Organisation. Addressing health inequalities in Indonesia, 2017. Available at http://www.who.int.

3. Chandalia M, Abate N, Garg A, StrayGundersen J, Grundy SM. Relationship between generalized and upper body obesity to insulin resistance in Asian Indian men. J Clin Endo Metab.1999;84:2329-35.

4. Misra A, Vikram NK. Insulin resistance syndrome (metabolic syndrome) and Asian Indians. Current Science. 2002:1483-96.

5. Vasan RS, Benjamin EJ, Levy D. Prevalence, clinical features and prognosis of diastolic heart failure: an epidemiologic perspective. J Am CollCardiol. 1995; 26:1565-74.

6. Rubler S, Deluges J, Yuceoglu YZ, Kumar T, Bran wood AW, Grishman A. New type of cardiomyopathy associated with diabetic glomerulosclerosis. Am J Cardiol 1972; 30:595 -602

7. Shindler DM, Kostis JB, Yusus S, Quinones MA, Pitt B, Stewart D, et al, Diabetes mellitus, a predictor of morbidity and mortality in the Studies of Left Ventricular Dysfunction (SOLVD) Trials and Registry. Am J Cardiol1996;77:101720.

8. Cosson S, Kevorkian JP. Left ventricular diastolic dysfunction: an early sign of diabetic cardiomyopathy. Diabetes Metab 2003;29:455-466.
9. Zarich SW, Nesto RW. Diabetic cardiomyopathy. Am Heart J2001;35:1668.

10. a). Sujino T, Kawasaki d, Bonow RO, New insights into diastolic heart failure. role of diabetes mellitus. Am $\mathrm{J}$ Med 2005;116(suppl6):34S-45S.

b). Vanninen E, Pitale SU. LV Function and dimensions in newly diagnosed noninsulin-dependent mellitus. Am J Cardiol1992;70:371-8

11. Yudkin, John S. "Vascular events and diabetes: Acute myocardial infarction and stroke", Ch. 64 in International Textbook of Diabetes Mellitus, Albertti K.G.M.M., Zimmet P., Defronzo R.A., England: John Wiley and Sons Ltd., Ed 2, 1997, 1827pp.

12. Sharavanan TKV, Prasanna KB, Ekanthalingam S, Sundaram A, Premalatha E, Arumugam B. A study on the prevalence of diastolic dysfunction in type 2 diabetes mellitus in a tertiary care hospital. IAIM.2016;3(7):216-22

13. Chaudhary AK, Aneja GK, Shukla S, Razi SM. Study on Diastolic Dysfunction in Newly Diagnosed Type 2 Diabetes Mellitus and its Correlation with Glycosylated Haemoglobin (HbA1C). J Clinic Diagnostic Res. 2015;9(8):OC20OC22.

14. Von Bibra H, St John Sutton M. Diastolic dysfunction in diabetes and the metabolic syndrome: promising potential for diagnosis and prognosis. Diabetologia. 2010;53(6):1033-45.

15. From AM, Scott CG, Chen HH. Changes in diastolic dysfunction in diabetes mellitus over time. Am J Cardiol. 2009;103:1463-6.

16. Cosson, S. \& Kevorkian, J. Left ventricular diastolic dysfunction: an early sign of diabetic cardiomyopathy. Diabetes and Metabolism .2003, 29(5): 455-466.

17. (a). Sanchez-Barriga JJ, Rangel A, Castaneda R, Flores D, Frati AC, et al. 
(2001) >GO ventricular diastolic dysfunction secondary to hyperglycemia in patients with type II diabetes. Arch Med Res 32: 44-47.

(b). Cosson S, Kevorkian JP (2003) >GO ventricular diastolic dysfunction an early sign of diabetic cardiomyopathy? Diabetes Metab 29: 455-466.

(c). Freire CMV, NunesMdo C, Barbosa MM, Longo JR, Nogueira AI, et al. (2006) dysfunction in diabetes: a condition of early left ventricular diastolic abnormalities. J Am SocEchocardiogr 19: 1251-1256. 